\title{
Joaquim Mattoso Câmara JR: Um InOvador
}

\author{
(Joaquim Mattoso Câmara Jr: Innovator)
}

Yonne LEITE

(CNPq/Museu Nacional/UFRJ)

\begin{abstract}
In this text we review Mattoso Câmara's different areas of interest phonology, morphology, stylistics - emphasizing his efforts toward the institutionalization of linguistic studies in Brazil: the creation of the discipline of General Linguistics in the 1930s; the establishment of a Linguistic Sector at the Museu Nacional in Rio de Janeiro, in 1958; the foundation of the Brazilian Linguistics Association, ABRALIN, in 1969. Mattoso's legacy is revisited here from the point of view of someone who was his student and witnessed the path followed by a whole generation of pioneer linguists, inspired by the master. Among others: Carlos Eduardo Falcão Uchôa, Miriam Lemle, Leda Bisol, Jean Pierre Angenot, Paulino Vandresen, Eunice Pontes, Brian Head, Cléa Rameh, Eurico Back and Yonne Leite herself.
\end{abstract}

KEY-WORDs: Mattoso Câmara; General Linguistics; Museu Nacional; ABRALIN.

Resumo: Neste texto são revistas as diferentes áreas de interesse de Mattoso Câmara - fonologia, morfologia, estilística - e enfatizados seus esforços para a institucionalização dos estudos lingü̈sticos no Brasil: a criação de uma disciplina em Lingüística Geral na década de 1930; o estabelecimento de um Setor Lingüístico no Museu Nacional, no Rio de Janeiro, em 1958; a fundação da ABRALIN, em 1969. O legado de Mattoso é revisitado do ponto de vista de quem foi sua aluna e testemunbou o percurso que, a partir do mestre, toda uma geração de lingüistas pioneiros percorreu. Entre outros: Carlos Eduardo Falcão Uchôa, Miriam Lemle, Leda Bisol, Jean Pierre Angenot, Paulino Vandresen, Eunice Pontes, Brian Head, Cléa Rameh, Eurico Back e a própria Yonne Leite.

PaLAVRAS-CHAVE: Mattoso Câmara; Lingüística Geral; Museu Nacional; ABRALIN. 


\section{Mattoso Câmara: o introdutor de um novo paradigma}

Este volume de trabalhos dedicados à memória do Professor Joaquim Mattoso Câmara Jr. vem saldar uma dívida da comunidade lingüística para com aquele que foi o idealizador da Associação que hoje nos congrega, o introdutor de um novo paradigma lingüístico em nosso país - a lingüística estruturalista -, o incentivador dos estudos de línguas indígenas, homem de muitos títulos, de muitas luzes, de vasta e variada produção científica, e de reconhecimento internacional. Doutor, livre-docente, jamais chegou a Professor-Catedrático. Fundador da Associação Brasileira de Lingüistica jamais almejou ser dela Presidente. Mas foi para todos aqueles que tiveram a oportunidade de assistir às suas aulas o professor-perfeito, o mestre que não se pode esquecer e a quem sempre se almeja imitar.

Repensar a obra de Joaquim Mattoso Câmara Jr. não é tarefa das mais fáceis, pois significa percorrer os vários caminhos por ele trilhados durante sua intensa vida de professor e pesquisador. Se, por um lado, há a alegria de constatar a perenidade que o trabalho acadêmico confere àqueles que se desempenham com seriedade e eficiência, por outro, fica a tristeza das lembranças de alguém com quem convivi por 10 anos no Setor de Lingüística do Museu Nacional e que não mais está entre nós: seus cabelos brancos, seu porte meio curvado, sua leitura constante, silenciosa e tranqüila, sua lhaneza no trato são recordações que guardarei aliada à sua maestria de exposição oral, suas aulas perfeitas, seu desejo intenso de transmitir tudo o que sabia, tudo o que lia.

Um breve exame de sua bibliografia nos mostra a diversidade de temas e campos por que se interessou em seu afã de não só entender o fenômeno da linguagem humana, em seus lados formais e estéticos, mas também de divulgar as potencialidades da nova disciplina, que ele introduziu no país, e que tanto encantou aos intelectuais brasileiros nas décadas de 50 e 60. Essa diversidade também se espelha em sua vida. Poeta em sua juventude, arquiteto e advogado por formação profissional, tudo abandona formalmente em 1937, para se dedicar integralmente ao magistério de nível secundário. É a eterna procura de um ser inquiridor e inquieto que o levou a cursar duas faculdades e à coragem de abandonar a segurança da profissão de arquiteto e advogado pelas incertezas da carreira de professor. É a mesma procura e a mesma coragem que o fazem nadar contra a correnteza 
da gramática tradicional que o levaria a um porto seguro e trilhar os caminhos de uma nova ciência, promissora, mas diáfana, encantadora, mas difícil.

Um olhar mais arguto nos mostra uma unidade e uma subjacência nessas escolhas e que o abandono é, por vezes, apenas aparente.

Deixou de escrever poesias, mas continuou a perseguir a musicalidade do verso e as sutilezas da linguagem literária. Seus estudos sobre versificação e estilística remodelaram e abriram novos caminhos para o fazer crítica literária no país e o levaram a penetrar o estreito e difícil meio da renomada lingüística norte-americana, então em seu ápice, publicando no conceituado periódico Word o artigo "Imperfect Rhymes in Brazilian Poetry" (Mattoso Câmara 1946). Captar e tornar explícita a simplicidade de estilo de Machado de Assis foi uma constante em sua vida como o provam os Ensaios Machadianos (Mattoso Câmara 1962a), volume em que reúne várias crônicas e artigos publicados em jornais e revistas literárias. Com a finura do mestre da língua portuguesa trata de temas pouco usuais como "Cão e Cachorro em Quincas Borba", "O coloquialismo em Machado de Assis", "A gíria em Machado de Assis", "O discurso indireto livre”, como se vê, todos girando em torno da linguagem comum transformada em estilo literário (cf. Mattoso Câmara 1962).

Deixou a arquitetura e o emprego de desenhista, mas continuou a buscar a forma, a geometria da linguagem e através dela seus meios e maneiras de modelar os mundos que nos rodeiam.

Deixou a advocacia e o formalismo codificado da jurisprudência e partiu à procura das intrincadas leis que regem a misteriosa e quase inacessível faculté du language que torna todos os homens iguais. Em Introdução às Língua Indígenas Brasileiras diz-nos "[...] ]do ponto de vista do lingüista a ária La donna è mobile tem o mesmo interesse, quer cantada por Gigli, quer cantada por mim, porque justamente o que determina a maestria de Gigli são os elementos que estão na parole, ou fala, mas não pertencem à língua" (Mattoso Câmara 1965a: 14).

Iniciou sua carreira no magistério como professor do ensino secundário e nela permaneceu, mesmo já tendo título de doutor e livre docente, aliando o ensino universitário com o de segundo grau até bem próximo do final de sua vida, dando aulas no Colégio Andrews. Seu primeiro artigo, 
cujo fac simile é publicado no volume Dispersos, organizado por Uchôa (1972), numa das mais belas homenagens póstumas já feitas a Mattoso Câmara e em que baseei as informações biográficas aqui apresentadas. Trata de um tema tradicional e ao gosto da época (1934): o uso de latinismos na linguagem burocrática. E já aí seu espírito inovador se revela, pois argumenta pelo aportuguesamento de formas latinas como memorandum, memoranda, denunciando o pretenso latinismo considerandum, posicionando-se contra o pedantismo e falsa cultura dos burocratas. A esse artigo seguiram-se vários outros, numa constância periódica, também marcante em sua vida, todos fazendo parte da seção Pequenas Lições de Português, publicada no Correio da Manhã, durante o ano de 1934. O rol de temas tratados nos mostra outra constante de sua produção: o gosto pela minudência, de observar o pouco observado, de fazer dos fatos corriqueiros da linguagem um objeto de reflexão. Vejamos, à guisa de ilustração, alguns desses títulos: "Um equívoco de três 'caturras", "Um erro de prosódia: espírita”, "Idólatra e alcoólatra”, "Por que 'quatriênio"?', "A expressão popular: 'menino levado", "Romancismo e Romancista", "Futebol" e vários outros em que a linguagem do cotidiano se torna alvo do olhar científico.

Privei com o professor Mattoso Câmara durante os últimos anos de sua vida. Um convívio diário no Setor de Lingüística do Museu Nacional, do qual foi o organizador. Dele herdei a sala e a mesa de trabalho, a cadeira giratória, as estantes e guardei na memória os ensinamentos e o exemplo, o desejo de sempre querer saber mais, a vontade de sempre ler mais. Gostaria imensamente de ter herdado também o espírito lúcido, a clareza da exposição e o amor ao trabalho.

Um amor tão grande que a tudo perpassava, que conseguiu transformar a tediosa e insípida tarefa de correção de redações do curso secundário num momento de pesquisa e de criação, detectando, nos erros ortográficos dos alunos, as tendências das mudanças da fonologia do português. $\mathrm{O}$ artigo que daí resultou (Mattoso Câmara 1957a), "Erros escolares como sintomas de tendências lingüísticas no português do Rio de Janeiro", veio não só servir de consolidar a análise fonológica que apresentou em seu clássico livro, Para o Estudo da Fonêmica Portuguesa, tese para a obtenção do grau de Doutor em Letras Clássicas, na Faculdade de Filosofia da Universidade do Brasil (1949), mas também inspirou, pelos parâmetros fixados, a dissertação de mestrado, O Adolescente e a Percepção do Valor Social de Variantes Lingüísticas, (1973) e a tese de doutorado A Transmissão ao Educando de Crenças 
e Atitudes Lingüísticas (1981), ambas defendidas na Faculdade de Letras da UFRJ, por Emmanoel dos Santos.

Antecipou-se, assim, Mattoso Câmara, à prática moderna, que tomou corpo e vigor com Fromkin (1971), em seu artigo "The Non Anomalous Nature of Anomalous Utterances", de procurar em erros e lapsos as evidências para as análises e arcabouços teóricos propostos.

\section{A contribuição fonológica}

Em 1953, a Organização Simões publicou em sua Coleção Rex um pequeno livrinho intitulado Para o Estudo da Fonêmica Portuguesa da autoria de J. Mattoso Câmara Jr.. Conforme nos diz o autor :

Para o Estudo de uma Fonêmica Portuguesa foi a tese com que obtive o grau de Doutor em Letras Clássicas na Faculdade Nacional de Filosofia em 1949. Apresentei, então, à Faculdade 5 exemplares datilografados apenas. Mais tarde publiquei no Boletim de Filologia (ed. Dois Mundos, Rio) nos números 9 e 10 respectivamente, o terceiro capítulo 'Os Fonemas do Português' que era a parte final e essencial da tese e o primeiro capítulo introdutório sobre 'Fonética e Fonêmica'. Ambos despertaram algum interesse aqui e no estrangeiro, sendo que os 'Fonemas do Português' mereceram resenha de Paul Garvin em Studies in Linguistics (vol. 8, no 4) e de Helmut Ludke no Boletim de Filologia de Lisboa (XII, 353) além de uma carta crítica de Antenor Nascentes. Julguei assim de bom alvitre aceitar o convite da Organização Simões para reuni-los em volume, o que aqui faço numa edição revista e um pouco ampliada. Deixei de lado o segundo capítulo sobre os 'Estudos Fonéticos em Português' que versava matéria marginal e talvez ex-crescente. Em compensação ajuntei um terceiro capítulo, um estudo sobre 'A Rima na Poesia Brasileira', remodelando ligeiramente a tese inédita que apresentei no Primeiro Congresso da Lingua Vernácula, organizado pela Academia Brasileira de Letras em homenagem ao Centenário de Rui Barbosa, porque esse trabalho é uma amostra das pesquisas que se pode fazer nas diretrizes dos princípios fonêmicos. (Mattoso Câmara 1953: Nota Prévia)

Prefácio modesto para um livro que é para mim um marco na história da lingüística brasileira. Não há um trabalho sobre fonologia do português do Brasil que não o cite e não o use como referência fundamental. Lembrando alguns, sem ordem determinada, temos: Miriam Lemle em sua dissertação de mestrado defendida na Universidade da Pensilvânia, intitulada Phonemic System of the Portuguese of Rio de Janeiro (Lemle 1966); Brian Head em sua tese de doutorado defendida na Universidade do Texas em Austin, A Comparison of the Segmental Phonology of Lisbon and Rio de Janeiro 
(Head 1964); Eunice Pontes, também em dissertação de mestrado intitulada Estrutura do Verbo no Português Coloquial, publicada pela Editora Vozes em 1972; Joanne Jeffreys Cyr em Some Intonational Features of Brazilian Portuguese, dissertação de mestrado defendida na Universidade do Texas em Austin (Cyr 1965); Clea Rameh, Contrastive Analysis of Portuguese Intonation, tese de mestrado defendida na Universidade de Georgetown (Rameh 1961).

Cumpre assinalar que mesmo teses que não são estritamente de fonêmica como a de Miriam Terezinha da Matta Machado, Étude Articulatoire et Acoustique des Voyelles Nasales du Portugais de Rio de Janeiro (Université de Strasbourg, 1981); Luiz Carlos Cagliari, An Experimental Study of Nasality with Particular Reference to Brazilian Portuguese (Universidade de Edimburgo, 1977) e de João Antonio de Moraes, Recherches sur l'Intonation Modale du Portugais Brésilien Parlé à Rio de Janeiro (Université de la Sorbonne Nouvelle, 1984) se apóiam na análise fonêmica de Mattoso Câmara para o delineamento da questão de que tratam. A bem da verdade, não há trabalho sobre a fonologia do português do Brasil que não cite e não use como referência a análise de Mattoso Câmara.

Os motivos de tão ampla penetração residem no fato de ser esta a primeira análise da fonologia do português do Brasil feita por um falante brasileiro e também porque praticamente não há um único problema de fonologia do português que esteja sendo, ou tenha sido estudado, que não esteja abordado, tratado, ou encaminhado em Para o Estudo da Fonêmica Portuguesa: a interpretação das vogais nasais e da vibrante múltipla, as vogais pretônicas e postônicas, o alteamento das vogais pretônicas, a velarização do $l$, os graus de tonicidade do vocábulo e sua função delimitativa, a vogal anaptítica, as vogais assilábicas orais e nasais, a distribuição das chiantes. Assim, o alteamento das vogais pré-tônicas foi primeiramente retomado por Miriam Lemle em "Analogia na Morfologia: estudo de um caso", com a finalidade de demonstrar que a diminuição da alomorfia nos paradigmas é um princípio mais forte para a regularização de formas do que a transparência das regras (cf. Lemle 1974). A assimilação das vogais pré-tônicas é tema de dissertação de mestrado e teses de doutorado, entre as quais destaco Leda Bisol, A Harmonização Vocálica, que estuda amplamente a ocorrência do fenômeno em Porto Alegre (Bisol 1981). A interpretação da vibrante múltipla recebe novo tratamento em artigo de Jean Pierre Angenot e Paulino Vandresen intitulado 'The Portuguese R's revisi- 
ted' (Angenot e Vandresen 1981), artigo que abordarei mais adiante. A questão das vogais assilábicas e da interpretação de glides e dos sons de transição são reinterpretadas na dissertação de mestrado de Eunice Pontes e na tese de doutorado de Brian Head referidas anteriormente. Mais uma vez Miriam Lemle reelabora os graus de tonicidade em sua dissertação de mestrado também já aludida. Para as vogais nasais são inúmeros os trabalhos referentes não só ao português do Brasil quanto ao de Portugal. Não me alongarei em enumerar todos os trabalhos que de um modo ou de outro se reportam à análise de Mattoso Camara porque a lista seria por demais grande. Deter-me-ei em apenas dois tópicos: as vogais nasais e a vibrante múltipla.

Antes, porém, se torna necessária uma caracterização mais ampla da teoria seguida por Mattoso Câmara. Ele foi adepto, talvez o único em nosso país, da fonologia do Círculo Lingüístico de Praga, cujos ensinamentos fora aprimorar nos Estados Unidos da América em 1943, com uma bolsa de estudos conferida pela Fundação Rockefeller. Foi aluno, tornando-se amigo, de Roman Jakobson. É essa fase de seu curriculum acadêmico, esse período de maturação lingüística, que ele nos traduz em Para o Estudo da Fonêmica Portuguesa. E o faz com o ardor, o ímpeto, a minúcia, o gosto de demonstração daqueles que se ausentam à procura de novos conhecimentos e que querem partilhar o que aprenderam e o que foi cuidadosamente construído. Assim, o quadro por ele apresentado do sistema vocálico é um exemplo de clareza de aplicação de uma teoria. Parte das oposições em posição tônica, estabelecendo 7 fonemas, que irão se neutralizar nas posições átonas: 5 arquifonemas na posição pré-tônica, 4 na posição pós-tônica medial e 3 na posição pós-tônica em final de palavra. A realização dos arquifonemas irá depender dos dialetos regionais, sendo que na posição pré-tônica a regra de alteamento das vogais médias tornará os contrastes pouco produtivos. Oferece-nos, deste modo, uma visão global e integradora. As descrições e estudos fonológicos que se seguiram infelizmente abandonaram essa perspectiva e tratam das vogais independentemente da acentuação. Se ganhamos, em alguns casos, em conhecimento factual, muito perdemos na síntese e na visão global e totalizadora. A linha de análise fonológica que irá vencer em nosso país não será a de Mattoso Câmara, mas sim a do estruturalismo distribucional norte-americano, a análise concreta do "uma vez fonema sempre fonema", em que as condições de biunivocidade, determinação local, invariança e linearidade serão rigidamente 
obedecidas. Nem o próprio Mattoso Câmara ficou totalmente infenso a essa corrente, como veremos mais adiante.

Disse que me deteria em duas de suas análises e as escolhi por serem as mais discutidas e polêmicas: a análise das vogais nasais e da vibrante múltipla.

Para as vogais nasais, as análises do português se dividem em aquelas que as consideram fonêmicas (Eunice Pontes, Robert Hall, Brian Head, Clea Rameh, Eurico Back, Yonne Leite) e as que as consideram não-fonêmicas (Mattoso Câmara, Miriam Lemle, David Reed e Yolanda Leite (1956), Moraes Barbosa, Maria Helena Mira-Mateus). Seguindo-se uma visão estruturalista concreta, tal como o faz Eurico Back, o problema poderia se resumir a uma questão de acuidade fonética, isto é, se reduziria à indagação de se existe ou não um glide consonântico nasal em final de palavras, como lã e fim, ou acontecendo outras consoantes, como em lâmpada, ânfora e manga. Para Back, em "São fonemas as vogais nasais do Português?"

A língua é falada para ser ouvida pelos outros. Aquilo que os falantes não ouvem, simplesmente, não existe em seu código lingüístico, portanto não é elemento da língua e não interessa ao lingüista, embora possa interessar a um foneticista, à Física Acústica (Back 1973: 308)

Para Mattoso Câmara, a questão é bem mais complexa do que a mera audição do glide nasal. É ele quem inaugura a linha de apresentar argumentos intra-sistêmicos para referendar sua análise. Assim, considera as vogais nasais como vogais orais seguidas de um arquifonema consonântico nasal, sendo a natureza nasalizada da vogal decorrente da consoante nasal que lhe trava a sílaba. Como argumentos de que uma vogal nasal funciona como se fosse travada por uma consoante apresenta a não-ocorrência da vibrante simples após vogal nasalizada e a refração à crase entre vogal nasal e outra vogal seguinte.

Nas análises pós-Mattoso Câmara, a questão passa a ser rebater ou endossar a argumentação acima citada e, admitida a existência do glide, debate-se sua interpretação. Pontes considera os glides nasais alofones das vogais nasais, Lemle, das consoantes nasais e Hall (1943), das consoantes não nasais. Tem-se, assim, um claro exemplo do que Chomsky chama fonêmica taxonômica. 
Um passo à frente, também dado por Mattoso Câmara, foi o de avaliar as conseqüências de sua análise em outros domínios da língua. Assim, reinterpreta a rima entre vogal oral e vogal nasal como sendo uma rima imperfeita e não, toante, como a caracteriza Celso Cunha.

Das análises estruturalistas propostas, a única que ameaça seriamente o arcabouço proposto por Câmara é a de Eunice Pontes, pois ela apresenta um par mínimo, caminha do verbo caminhar e caminha, diminutivo de cama, em que a vogal oral seguida de consoante nasal contrasta com a vogal nasal seguida de consoante nasal, contraste esse que a análise de Mattoso Câmara não dá conta, ou o dá de modo inadequado.

Um dos pontos mais contestados da proposta de Mattoso Câmara é a análise da vibrante múltipla. Não vê ele no par caro: carro o contraste entre dois fonemas, mas sim a ocorrência de uma vibrante simples em caro e uma consoante geminada em carro. Nesta, o primeiro elemento da geminação não se realiza foneticamente. Usando as próprias palavras do autor:

Podemos admitir que o /r/ pós-vocálico, foneticamente perceptível em ar roxo, existe potencialmente em arrocho, embora sem realização fonética; a sua presença fonêmica manifesta-se apenas pela manutenção do /r/ seguinte, que ficou fonemicamente nãointervocálico (Mattoso Câmara 1953:109).

A comprovação para essa interpretação ele vai buscar nos lapsos de pronúncia caminho esse, mais uma vez frisamos, amplamente difundido atualmente. Assim, a forma cirrugião por cirurgião seria explicada pela metátese do /r/ pós-vocálico da segunda sílaba para a primeira, deixando este de ser, então, intervocálico e tornando-se uma vibrante forte. $\mathrm{O} / \mathrm{r} /$ metatesizado, ao contato com o /r/ da primeira sílaba, anula-se foneticamente.

Nenhum dos estudos estruturalistas que o seguiram aceita a proposição de Mattoso Câmara. Barbosa (1962) é o estruturalista que mais debate e refuta essa interpretação, seguido de Brian Head. A razão mais aventada é a de que essa análise revive fatos históricos não mais atuantes nas regras do português moderno.

O próprio Mattoso Câmara não ficou imune a essas críticas. Muda sua análise da vibrante e em Problemas de Lingüística Descritiva já passa a falar em variantes livres do /r/ forte, colocando-o entre barras inclinadas, a indicar uma unidade fonêmica distinta do /r/ fraco (cf. Mattoso Câmara 1969). 
Em The Portuguese Language, Mattoso Câmara (1972) apresenta um novo fonema resultante da história do português: o /r/ fraco em oposição ao /r/ forte. E, em Estrutura da Língua Portuguesa, sua nova posição se torna clara ao apresentar dois fonemas em contrate no par era: erra (cf. Mattoso Câmara 1970).

Acompanhei de perto essa mudança e acho que nela pesou muito, não só as críticas feitas, mas também o diálogo constante e diário com lingüistas do Summer Institute of Linguistics, que trabalhavam em convênio com o Museu Nacional. A abordagem por eles seguida, e que muito influenciou a prática lingüística em nosso país, jamais aceitaria essa análise por ser muito abstrata, distanciada da realidade fonética.

Mattoso Câmara presenciou a ascensão da teoria chomskiana e da fonologia gerativista. E tinha-lhe uma profunda aversão. Manteve-se sempre alinhado às hostes estruturalistas. Conhecia, porém, muito bem suas propostas e estava perfeitamente em dia em suas leituras.

Esse repúdio é para mim ao menos curioso. Curioso porque os pontos mais controvertidos e atacados de sua análise encontrariam na nova teoria uma guarida.

A teoria gerativista fornece os meios para contornar o sério empecilho, mencionado anteriormente, aventado por Eunice Pontes, para considerar as vogais nasais como não-fonêmicas. Basta se apelar para a aplicação cíclica de regras, admitindo-se a informação morfológica e limitar a nasalização da vogal à posição tônica, como o fez Perini (1973), em The Process of Nasalization: Evidence from Portuguese. Desse modo, no primeiro ciclo, terse-ia a acentuação de cama + inha recaindo no primeiro $a$ da raiz. Este acento seria o responsável pela nasalização de caminha "diminutivo de cama". Já em caminha do verbo caminhar, o $a$ não seria acentuado e não se nasalizaria. Todas as análises gerativas do português, menos a de Leite (1974) e a de Abaurre-Gnerre (1983), consideram a vogal nasal como não-fonêmica. E mais, Harris (1969), em seu clássico livro Spanish Phonology, defende brilhantemente a posição de considerar, para o espanhol, uma consoante geminada no caso do /r/ forte. É verdade que, para o português, o trabalho mais completo de que se dispõe em linha gerativista, o de Mateus (1982), rebate a interpretação para $\mathrm{o} / \mathrm{r} /$, assim como qualquer outra análise que postule consoantes geminadas para o português. 
Mais recentemente, usando o arcabouço da fonologia natural, pura, Angenot e Vandresen (1981) reabilitam essa interpretação de Mattoso Câmara. Reanalisam a questão como uma decorrência da estrutura silábica. No caso do /r/ forte de carro, tem-se uma sílaba travada por uma consoante subjacente não definida, um infra-segmento, como denominam, que tem especificado apenas o traço [-silábico], sendo todos os outros traços zeros. $\mathrm{O}$ formalismo apresentado é muito elaborado, mas pode-se ver muito bem que o infra-segmento que se realiza como zero nada mais é do que o primeiro membro da geminação que se anula foneticamente, tal como estabelecido por Mattoso Câmara.

A coincidência entre alguns pontos das propostas de Mattoso Câmara e a teoria gerativista se torna mais patente se lembrarmos o seu artigo "A Note on Portuguese Noun Morphology”, publicado no volume em homenagem a Roman Jakobson, por ocasião do seu septuagésimo aniversário. A formação do plural das palavras terminadas em -ão é aí reanalisada e são propostos o que Mattoso Câmara denomina 'padrões' que se combinam com classes morfológicas e estruturas fonológicas, padrões esses de onde se produziriam as formas singulares e plurais. O mecanismo é de estabelecer a forma padrão do plural. Assim, para leão: leões, tem-se o padrão leõe, fonologicamente, leoN (cf. Mattoso Câmara 1967). Ora, esse procedimento é exatamente o mesmo seguido nas análises de Hensey (1968), St. Clair (1971), Brasington (1971), Mateus (1982), com o intuito de mostrar a superioridade da abordagem gerativista sobre as tradicionais e as estruturalistas. O que esses autores oferecem a mais são os mecanismos por que se chega dessas formas abstratas às formas de superfície, ponto esse totalmente obscuro na proposta de Mattoso Câmara.

Há, porém, uma diferença fundamental entre a prática de Mattoso Câmara e a dos gerativistas. Para estes, estas formas têm uma motivação independente e uma realidade psicológica. Explicam não só a formação do plural, mas também a colocação do acento tônico, tornando-o nãofonêmico, a formação do feminino e a regra de abrandamento velar. Para Mattoso Câmara são apenas construtos teóricos, um meio engenhoso, justificável pela evolução histórica, restrito à análise de um determinado grupo de fenômenos da formação do plural.

Sua contribuição fonológica é, sem dúvida, a parte de sua obra mais conhecida. A análise dela empreendida por Bisol (1996), fonóloga de grande 
expressão e reconhecida pelo seu espírito também inovador, não deixa dúvida da perenidade dos problemas de análise levantados por Mattoso Câmara.

Menos conhecido, no entanto, é o papel por ele desempenhado na institucionalização do campo das línguas indígenas brasileiras, o que relatarei a seguir.

\section{A reinvenção das línguas indígenas}

Conheci o Prof. Mattoso Câmara, a quem fui procurar por querer trabalhar com línguas indígenas brasileiras, em fins de 1959, recém-chegada dos Estados Unidos de uma bolsa de estudos para onde fora, com mais oito brasileiros, colher informações e observar o sistema educacional americano. Minha descoberta do campo das línguas indígenas brasileiras se deve, como em tantos outros casos, a um mero acaso. Foi no Instituto de Verão de 1958, patrocinado pela Linguistic Society of America e realizado na Universidade de Michigan, que tomei conhecimento de que, no Brasil, existiam línguas indígenas ainda faladas, línguas vivas em estruturas passíveis de serem estudadas. Para mim, dos bancos escolares ficara a idéia de que no Brasil houvera outrora uns índios - desaparecidos todos - que falavam tupi-guarani, moravam em taba, tinham um cacique denominado morubixaba, um Deus que era o Tupã e curandeiros conhecidos por pajé. E mais, era um povo nômade, que vivia da caça e da pesca. Era um povo sem fé, nem rei, nem lei, pois não havia em sua língua os sons $f$, $r$ e $l$.

Esse desconhecimento não era só meu. Em comunicação intitulada "A concepção dos lingüistas”, apresentada na XIII Reunião Brasileira de Antropologia, realizada em São Paulo em 1982, Bruna Franchetto e eu procuramos, através de depoimentos, traçar a trajetória daqueles que, na época, trabalhavam com línguas indígenas, tendo realizado pesquisa de campo. A resposta mais freqüente à pergunta "Como chegou ou escolheu a área das línguas indígenas brasileiras?” Foi “por acaso” (Franchetto \& Leite 1983).

Também foi um acaso que me conduziu ao Museu Nacional. Descoberto o objeto de estudo, como acessá-lo? Foi num jantar durante o qual me queixei a um jovem antropólogo, também conviva, de que, no Brasil, não poderia fazer o que me motivava, que obtive a informação de que no 
Museu Nacional havia sido criado um setor de lingüística, cujo objetivo era o estudo das línguas indígenas e dos falares regionais brasileiros. À frente do Setor Lingüístico se achava Joaquim Mattoso Câmara Jr. No dia seguinte, após longa viagem de ônibus, aportava eu no Museu Nacional para oferecer minha força de trabalho e minha mente àquilo que me parecia então uma aventura fantástica.

O Professor Mattoso me recebeu de braços abertos e tornei-me sua estagiária. Assim, abandonei a trilha conhecida das línguas e literaturas neolatinas para adentrar o mundo desconhecido das línguas ágrafas, espaço aberto pelo Professor Mattoso Câmara.

Pouco tempo depois, chegava uma segunda aventureira: Miriam Lemle, que queria se especializar em Lingüística. O lugar era, então, o Museu Nacional, onde se realizavam seminários e os membros do Summer Institute of Linguistics ensinavam fonética, fonologia, morfologia e sintaxe. Tudo com muitos exercícios baseados em línguas não indo-européias e seguindo o modelo pikeano. Após uma incursão no campo das línguas indígenas, em que produziu o seminal artigo referencial "Internal classification of Tupi-Guarani linguistic family", Lemle enveredou pelos caminhos da língua portuguesa, passando a desenvolver seu trabalho na Faculdade de Letras da UFRJ.

O Setor Lingiüístico, do qual Mattoso Câmara era o 'Encarregado', foi criado por Luiz de Castro Faria com o intento de modernizar o Departamento de Antropologia do Museu Nacional, até aquele momento voltado para a pesquisa em Antropologia Física, Arqueologia e Etnografia. Além de Mattoso Câmara, Castro Faria convocou o jovem antropólogo que me informara sobre o Museu Nacional, Roberto Cardoso de Oliveira, para instalar a área de Antropologia Social, introduzindo os escritos de antropólogos ingleses e do antropólogo francês Claude Lévi-Strauss. Mattoso Câmara foi colega de Lévi-Strauss nos cursos de Roman Jakobson nos Estados Unidos e foi desse período que resultou sua tese de doutorado Para 0 estudo da fonêmica portuguesa (1953).

O clima e o ambiente eram altamente favoráveis à Lingüística que gozava, então, de enorme prestígio. Segundo Lévi-Strauss, seria a Lingüística a fornecedora de um método científico - oriundo da depreensão do fonema e da Fonologia - a ser copiado e importado pelas demais disciplinas das Ciências Humanas. 
Além disso, era consensual que a chave para o entendimento efetivo de uma sociedade estaria em sua língua, pois ela é que forneceria os recortes da realidade a ela externa. Para Sapir, a linguagem é socialmente condicionada e influencia o modo por que uma comunidade apreende a realidade. Ora, o mister do antropólogo, ao estudar uma sociedade, é depreender as categorias internalizadas pelos membros dessas comunidades e chegar à visão do mundo que compartilham. O ofício do antropólogo é captar e traduzir como pensa e sente a comunidade que investiga. Se na língua estão cristalizadas as categorias básicas do pensamento, seu entendimento é indispensável para a verificação das hipóteses analíticas apresentadas.

Mattoso Câmara tinha um trabalho excepcional em fonologia e, como já dissemos, fora aluno de Jakobson e colega de Lévi-Strauss. Além disso, traduzira a obra principal de Edward Sapir, A Linguagem: Introdução ao Estudo da Fala (Sapir 1954[1938]), e uma coletânea de artigos, a que deu o sugestivo nome Lingüística como Ciência: Ensaios (Sapir 1961). Nessa coletânea se encontra o texto "Lingüística como Ciência", no qual Sapir expressa, de maneira clara e concisa, a íntima e complexa relação entre linguagem, pensamento e realidade. A adesão e aceitação de Mattoso Câmara ao modo de pensar da lingüística sapiriana também se evidencia em seu artigo "Êle comme un accusatif dans le Portugais du Brésil" (Mattoso Câmara 1957b), no qual a proposta de explicação de substituição da forma átona $0, a, o s$, as muito se aproxima da aventada por Sapir para o uso de $w$ ho por whom em inglês. Para ambos, são fatores sistêmicos e funcionais, assim como a deriva (inglês drift, termo caro a Sapir) da língua que condiciona e favorece uma determinada mudança sintática e morfológica. Mais uma inovação, tipicamente estruturalista, que fugia ao modelo preconizado tradicionalmente.

A relação por ele aceita entre língua e cultura também se evidencia na adoção, em Princípios de Lingüística Geral (1964), da conceituação de cultura de Kroeber. Segundo o antropólogo norte-americano, em todas as criações humanas se estabelecem três níveis, a cujo conjunto se dá o nome de cultura: o inorgânico, o mundo físico; o orgânico e o super-orgânico, o mundo cultural. Os sons, fenômenos físicos, pertencem ao mundo inorgânico ao qual se superpõem os fenômenos biológicos, isto é, a sua produção pelos órgãos vocais. Porém, a linguagem só se atualiza quando os sons criam a comunicação no nível super-orgânico, quando, como a cultura, 
adquire um valor humano. A língua é parte da cultura, mas dela se destaca por ser resultado ou súmula, o meio por que a cultura opera, a condição para que ela subsista. A língua é, pois, parte da cultura e, ao mesmo tempo, a engloba e, através dela, pode a cultura se transmitir e se perpetuar, pois é a linguagem que a expressa. A linguagem tem seu lado físico: os sons. A cultura também: a habitação, as indumentárias, os artefatos, a chamada cultura material, estudada pela etnografia. E ambas têm o seu lado mental. Na língua, os fonemas, os morfemas, os semantemas. $\mathrm{Na}$ cultura, a religião, o parentesco. Porém, Lingüística e Antropologia não se confundem em suas partes mentais abstratas, mas se inter-relacionam.

É fácil ver porque a restrita comunidade antropológica recebeu Mattoso Câmara com carinho, respeito e admiração. Dominava ele os pressupostos teóricos da Lingüística, conhecia Fonologia, a disciplina cult da época, e correlacionava Lingüística e Antropologia, não fundindo uma disciplina na outra, mas mostrando a especificidade e os pontos comuns, epistemológicos, de cada uma.

Ao assumir a tarefa de reverter a situação de desconhecimento das línguas indígenas brasileiras teria que 1) dar a essas línguas o estatuto de línguas válidas, não-primitivas, como era voz corrente nos livros didáticos e 2) institucionalizar o estudo, promovendo pesquisas de campo e ampliando o saber na área.

Desempenhou essa função graciosamente. Pelo muito que deu, recebeu em troca uma sala de trabalho e o reconhecimento e a amizade de todos nós. Na então Faculdade de Filosofia da Universidade do Brasil era professor-adjunto de uma disciplina isolada, ministrada em dois semestres para os alunos de Letras anglo-germânicas e Letras clássicas. Os graduandos em Letras neolatinas, dado o acúmulo de disciplinas, não tinham horário para fazer seu curso. Esta é a razão por que não o conheci nos meus tempos de graduação.

Nessa tarefa se empenhou com ardor. Seu interesse pelas línguas indígenas era antigo, assim como seu afã de divulgá-las. Em 1934 já publicara, em sua seção semanal no Correio da Manhã , a crônica "O ensino do Tupi”. Para mostrar a importância dessas línguas, traduziu resenhas feitas por lingüistas famosos de trabalhos de descrição, como as de Paul Garvin sobre a língua dos Caxinawás do rio Ibauçu (Garvin 1946); o criterioso trabalho de Capistrano de Abreu (1941[1914]), e o de Plínio Ayrosa et alii, Etnogra- 
fia e língua Tupi-Guarani, (Ayrosa et al. 1947), assim como a de George Trager sobre o trabalho de Jurn Jacob Philipson, O Parentesco Tupi-Guarani (Philipson 1947). Traduziu também artigos como o de Kietzmann (1958), "Tendências de ordem lexical da aculturação lingüística Terena”. Utilizouse do que denominava Crônicas Lingüísticas, nas quais divulgava as últimas novidades como "A Glotocronologia" e "A Estatística Léxica" (cf. Mattoso Câmara 1959/1960), ou "A Conferência de Indiana entre Antropólogos e Lingüistas" (cf. Mattoso Câmara 1955a). Seus artigos são modelares. "Língua e Cultura” (1955b) foi vertido para o inglês por Paul Garvin, a fim de ser usado pelos alunos do Institute of Languages and Linguistics da Georgetown University of Washington (cf. Uchôa 1972, "Introdução").

É impar, a meu ver, a exposição e argumentação apresentadas em "Da natureza das línguas indígenas” (Mattoso Câmara 1962b) contra o etnocentrismo lingüístico prevalescendo até mesmo nos meios acadêmicos. Opõe-se aí a Levy-Bruhl, a Sommerfelt e Malinowski, que estabeleceram uma cisão entre línguas primitivas e língua de civilização. Mattoso apontou a inexatidão da análise ali apresentada e, conseqüentemente, das posições teóricas postuladas, mostrando que os fenômenos ditos primitivos também existem nas línguas de civilização. O mais importante é deter-se no estudo da oralidade, demonstrando que, vistas desse ângulo, as línguas são todas iguais. O que as distingue é a normatização e compleição que se encontram na escrita, descontextualizada que é do ato da fala. As idéias desse artigo estão reproduzidas no primeiro capítulo da Introdução às Línguas Indígenas Brasileiras (1965a) com o título "Em que se caracterizam as línguas indígenas?”

Sua incursão na análise de dados se faz em Alguns Radicais Jê (Mattoso Câmara 1959a), em que reanalisa e compara o material histórico disponível sobre línguas da família Jê, composto basicamente de listas vocabulares. O inovador é que depreende os processos, as regras do consonantismo e vocalismo que ocorreram nessa família lingüística. Até então era comum a classificação genética se basear apenas na semelhança entre as palavras. O procedimento do comparativismo clássico de se estabelecerem as regras que determinam as inovações compartilhadas e classificações internas das línguas será retomado por Lemle (1971).

Sem dúvida, porém, sua obra magna é o livro que até hoje não encontrou substituto, apesar de todos os avanços feitos no campo, Introdução às 
Línguas Indígenas Brasileiras (1965a), resultado de um curso dado, em 1960, aos antropólogos do Museu Nacional. As aulas foram gravadas, transcritas e com pouquíssimas correções estavam prontas para a publicação. Algo muito incomum. Já em 1943, o Professor Mattoso Câmara dera, a convite da então diretora D. Heloísa Alberto Torres, um curso especial de Lingüística para os etnólogos do Museu Nacional. O curso de 1960 foi, pois, uma segunda experiência bem sucedida. Tente alguém gravar suas aulas e delas fazer um livro... Em 10 capítulos, Mattoso Câmara faz uma revisão do histórico das pesquisas lingüísticas no Brasil, a análise crítica das diferentes orientações teóricas, traçando também diretrizes para a solução dos nossos problemas. Há um suplemento sobre a "Técnica da Pesquisa", aulas que foram dadas pela Dra. Sarah Gudschinsky, do Summer Institute of Linguistics. Há um reparo a fazer aqui. Não concordo com a crítica feita à Gramática Mais Usada na Costa do Brasil de que o Padre Anchieta tivesse regularizado a língua Tupi e seguido o modelo da gramática latina, adulterando as categorias genuínas e o valor dos morfemas. Minha leitura difere bastante da de Mattoso Câmara. Para mim, Anchieta mantém as categorias genuínas da língua, tanto que é possível comparar seus dados com os das línguas modernas examinadas à luz de teorias atuais.

A Mattoso Câmara coube, pois, a crítica revisionista e a avaliação das diferentes posições teóricas. Ao Summer Institute of Linguistics coube a parte prática. Desde 1959, o Summer tinha, no Museu Nacional, a sua sede no Brasil, através de um acordo firmado e aprovado em todas as instâncias universitárias. O Summer tinha reconhecida competência na arte de analisar línguas ágrafas. Sua finalidade era chegar a uma língua escrita para nela traduzir a Bíblia. Com apoio de lingüistas renomados como Morris Swadesh e Norman McQuown, detentor de uma metodologia eficiente e rápida, o S.I.L. realizava no México um trabalho lingüístico de ampla aceitação reconhecido pela Linguistic Society of America. Tinha o Summer em Kenneth Pike o seu ideólogo e teórico, que nos oferecia uma perspectiva que hoje chamaríamos de 'taxionomista extremada', seguindo à risca as condições de biunivocidade, linearidade, determinação local e invariância.

A visão mentalista de Mattoso Câmara, que o aproximava de Edward Sapir, naturalmente o afastava do behaviorismo e mecanicismo de Leonard Bloomfield, a linha seguida pelos membros do S.I.L.

Mattoso Câmara soube contornar todas essas diferenças e a relação com o Summer transcorreu de modo muito tranqüilo. Dividiu o espaço 
acadêmico por ele criado, incentivou as pesquisas de campo do S.I.L., empenhou-se por elas, não interferiu, nem tentou influenciar.

A publicação O Setor Lingüístico do Museu Nacional: Organização e Objetivo (Mattoso Câmara 1965b) é um testemunho dessa época e consagra o casamento feliz entre um lingüista idealista e funcionalista e os behavioristas distribucionistas. A união foi um sucesso. Em pouco tempo 20 línguas foram analisadas, um livro com vários artigos foi publicado (edição bilíngüe) mostrando os resultados de análise. Várias análises fonológicas, assim como diversos Formulários para 'Estudos Comparativos nas Línguas Indígenas Brasileiras', do qual constam os 200 termos básicos de Morris Swadesh, foram arquivados no Museu Nacional.

Na sala do Professor Mattoso Câmara era comum um ambiente de trocas lingüísticas das quais participavam Sarah Gudschinsky, Ursula Wiesemann, Loraine Bridgemann, Ivan Lowe, Dale Kietzmann, Luiz de Castro Faria, Roberto Cardoso de Oliveira. Quem visitasse o Rio de Janeiro, por lá passava. Kenneth Pike fez conferências no Museu Nacional nas quais demonstrava a excelência de sua metodologia, colhendo dados de uma língua ágrafa e oferecendo à platéia encantada, em uma hora, uma análise preliminar de sua fonologia, morfologia e sintaxe. Mas quem Mattoso Câmara convidou pessoalmente para dar palestras foi Roman Jakobson...

Além dos trabalhos já citados, Mattoso Câmara (1959b) redescobriu a parte lingüística do etnólogo alemão Curt Unkel Nimuendaju e publicou uma análise de seu sistema de notação, avaliando as informações lingüísticas.

Mattoso Câmara sempre agiu como um Maestro que respeitava a interpretação dos solistas. E foi com esse espírito que colaborou no Programa de Pós-Graduação em Lingüística, criado em 1968, sob a direção de Aryon Dall'Igna Rodrigues, com o apoio da Fundação Ford. Mattoso Câmara participou das negociações, deu seu nome, deu aula e, mais uma vez, cedeu seu espaço, deixando a organização e a coordenação a quem, a seu ver, tinha mais condições. Aryon Rodrigues já organizara e conduzira o mestrado em Lingüística na Universidade de Brasília, a primeira experiência no gênero no país, totalmente desarticulada com o golpe militar de 1964. Aryon Rodrigues veio, então, com uma bolsa de pesquisador, trabalhar no Museu Nacional, reproduzindo sua experiência de Brasília.

Um exame mais detalhado da contribuição de Mattoso Câmara no campo das línguas indígenas nos revela sua delicada intuição. Todos os 
temas por ele tratados tiveram continuação. Irvine Davis retoma o trabalho de classificação das línguas Jê em dois artigos que tratam tanto dos agrupamentos internos da família, quanto das relações entre as famílias, o Tronco Macro-Jê; o maior monumento da obra lingüística de Curt Nimuendajú, o Atlas Etnobistórico, foi alvo de uma caprichosa publicação por iniciativa do I.B.G.E., com a colaboração de lingüistas do Museu Nacional (cf. Nimuendajú 1981). O campo das línguas indígenas se institucionalizou e a apresentação dos trabalhos de análise não se restringe mais aos Congressos de Antropologia. Hoje se têm vários núcleos - Universidade de Brasília, Unicamp, Universidade Federal de Pernambuco, Museu Paraense Emilio Goeldi, Universidade Federal do Pará, Universidade Federal de Goiás, Museu Nacional - que congregam pesquisadores com trabalho in loco com línguas indígenas. Várias dissertações de mestrado e teses de doutorado foram defendidas no país e no exterior.

De sua ação entre nós fica o exemplo de quem não temeu as dificuldades, de quem teve a coragem de propor algo novo, de quem seguiu o caminho que julgava certo, por mais estranhas que suas idéias parecessem. E o fez com modéstia, dividindo o espaço conquistado, agregando e não separando, deixando que outros também a seu modo e à sua maneira também fizessem.

O exame da obra de Mattoso Câmara nos mostra que não se deve temer nem negar o passado, mas nele mergulhar sempre que pudermos, não apenas para reverenciá-lo e para entender o presente, mas acima de tudo para compreendermos o relativismo que o hoje e o atual implicam e significam, principalmente numa ciência tão mutante e dinâmica como a Lingüística. Em Mattoso Câmara, a distância entre o ontem e o hoje se esvai, pois em seus trabalhos se encontra muito do hoje, sua integridade intelectual e moral o tornam muito próximo e presente, aquele a quem se pode recorrer em pensamento nos momentos difíceis e de dúvidas pelo exemplo de determinação e coragem de defender suas posições e idéias que nos deixou.

E-mail: yfleite@domain.com.br 


\section{REFERÊNCIAS}

Abaurre-Gnerre, Maria Bernadete. 1983. Alguns Casos de Formação de Plural em Português: uma Abordagem Natural. Cadernos de Estudos Lingüísticos, 5: 127-156.

Angenot, Jean Pierre e Paulino Vandresen. 1981. The Portuguese R's revisited. In: Studies in Pure Natural Phonology and Related Topics. UFSC Working Papers in Linguistics.

Ayrosa, Plínio et al. 1947. Etnografia e Língua Tupi-Guarani. (Trad. de J. Mattoso Câmara Jr. da resenha de Paul Garvin). Boletim de Filologia, 2: 3. 37-40. Rio de Janeiro: Dois Mundos.

BACK, Eurico. 1973. São fonemas as vogais nasais do Português? Construtura, 4: 297-318.

BARBOSA, J. Moraes. 1962. Les voyelles nasales portugaises: interprétation phonologique. In: Proceedings of the Fourth International Congress of Phonetic Sciences. (Helsinki 1961). The Hague: Mouton.

Bisol, Leda. 1981. Harmonização Vocálica. Tese de Doutorado. Faculdade de Letras, UFRJ.

1996. Mattoso Câmara: uma presença na fonologia do português. Estudos Lingüísticos, 25: 20-27. Taubaté: GEL/ UNITAU.

Brasington, R. W. P. 1971. Noun pluralization in Brazilian Portuguese. Journal of Linguistics, 7. 2: 151-77.

Cagliari, Luiz Carlos. 1977. An Experimental Study of Nasality with Particular Reference to Brazilian Portuguese. Tese de Doutorado. Universidade de Edimburgo.

Capistrano de Abreu, João. 1941[1914]. Ra-Txã Hu-Ni-Ku-Ĩ. A Lingua dos Caxinauás do Rio Ibuaçu, Affluente do Murú. Prefeitura de Taraucá. Rio de Janeiro: Sociedade Capistrano de Abreu. (1a. ed., Rio de Janeiro: Typographia Leuzinger, 1914).

Cyr, Joanne Jeffreys. 1965. Some Intonational Features of Brazilian Portuguese. Dissertação de Mestrado. Departamento de Lingüística, Universidade do Texas, Austin.

Franchetto Bruna e Yonne Leite. 1983. A concepção dos lingüistas. Cadernos de Lingüístical Série especial, 4: 15-30.

Fromkin, Victoria. 1971. The non anomalous nature of anomalous utterances. Language, 47. 1: 27-52.

Garvin, Paul. 1946. Resenha do Rã-txa bu-ni-ku-i: a Lingua dos Caxinauás, de J. Capistrano de Abreu (Trad. de Joaquim Mattoso Câmara). Boletim de Filologia, 1:4. 231-233. 
Hall Jr. Robert, A. 1943. The units phonemes of Brazilian Portuguese. Studies in Linguistics, 15: 1-16.

Harris, James W. 1969. Spanish Phonology. Cambridge, Mass.: The M.I.T. Press.

HeAD, Brian. 1964. A Comparison of the Segmental Phonology of Lisbon and Rio de Janeiro. Tese de Doutorado. Departamento de Lingüística, Universidade do Texas, Austin.

Hensey, Fritz. 1968. Questões de fonologia gerativa: as regras de pluralização. Estudos Lingüústicos, 3: 1-10.

Kietzmann, Dale. 1958. Tendências de ordem lexical da aculturação lingüística terena. Revista de Antropologia, 6: 1. 22-32. São Paulo: Universidade de São Paulo.

Leite, Yonne. 1974. Portuguese Stress and Related Rules. Tese de Doutorado. Departamento de Lingüística, Universidade do Texas, Austin.

1986. "O Pensamento Fonológico de J. Mattoso Câmara Jr.". ABRALIN, 7: 17-24.

1991. Unidade e diversidade na vida e na obra de J. Mattoso Câmara Jr. ABRALIN, 12: 193-199.

Lemle, Miriam. 1966. Phonemic System of the Portuguese of Rio de Janeiro. Dissertação de Mestrado. Universidade da Pensilvânia.

1971. Internal classification of tupi-guarani linguistic family. In: David Bendor Samue (ed). Tupi Studies I. Oklahoma: Summer Institute of Linguistics.

1974. Analogia na Morfologia: estudo de um caso. Revista Brasileira de Lingüistica, 1: 1-14.

Mateus, Maria Helena Mira. 1982. Aspectos da Fonologia Portuguesa. 2a. ed. Lisboa: Instituto Nacional de Investigação Científica/ Centro de Lingüística da Universidade de Lisboa.

Matta Machado, Miriam Terezinha da. 1981. Étude Articulatoire et Acoustique des Voyelelles Nasales du Portugais de Rio de Janeiro. Tese de Doutorado. Université de Strasbourg.

Mattoso CÂmara Jr., Joaquim. 1946. Imperfect Rhymes in Brazilian Poetry. Word, 2. 2:131-135.

. 1953. Para o Estudo da Fonêmica Portuguesa. Rio de Janeiro: Organização Simões.

1955a. Crônica Lingüística: A Conferência de Indiana entre Antropólogos e Lingüistas. Revista Brasileira de Filologia, 1: 2; 187-195. Rio de Janeiro: Acadêmica. 
1955b. Língua e cultura. Letras, 4: 51-59. Universidade do Paraná. 1957a. Erros escolares como sintomas de tendências lingüísticas no português do Rio de Janeiro. Romanistiches Jahrburg, 8: 279-86.

1957b. 'Êle' comme un accusatif dans le Portugais du Brésil. In: Miscelanea homenaje a André Martinet: estruturalismo y historia. Universidad de la Laguna. Vol. 1.

1959a. Alguns Radicais Jê. Publicações avulsas n 28. Rio de Janeiro: Museu Nacional.

1959b. A obra Lingüística de Curt Nimuendaju. Publicações avulsas $\mathrm{n}^{\circ} 29$. Rio de Janeiro: Museu Nacional.

1959/1960. Crônica Lingüística: Glotocronologia e Estatística Léxica. Revista Brasileira de Filologia, 5: 1/2. 209-215. Rio de Janeiro: Acadêmica.

1962a. Ensaios Machadianos: Lingua e Estilo. Rio de Janeiro: Acadêmica.

1962b. Da natureza das línguas indígenas. Revista de Letras, 3 : 17-29. São Paulo: Faculdade de Filosofia, Ciências e Letras de Assis.

1964. Princípios de Lingüistica Geral. Como Introdução aos Estudos Superiores da Lingua Portuguesa. 4a. ed. rev., ampl.. Rio de Janeiro: Acadêmica.

1965a. Introdução às Línguas Indígenas Brasileiras (com suplemento sobre a técnica de pesquisa por Sarah Gudschinsky). Rio de Janeiro: Museu Nacional.

1965b. O Setor Lingüístico do Museu Nacional: Organização e Objetivos. Publicações avulsas $n^{\circ}$ 49. Rio de Janeiro: Museu Nacional.

1967. A note on Portuguese noun morphology. In To Honor Roman Jakobson. Essays on the Occasion of his Seventieth Birthday 2: 1311-1314. The Hague: Mouton.

1969. Problemas de Lingüistica Descritiva. Petrópolis: Vozes.

1970. Estrutura da Lingua Portuguesa. Petrópolis: Vozes.

1972. The Portuguese Language: History and structure. Chicago: University of Chicago Press.

Moraes, João Antonio. 1984. Recherches sur l'Intonation Modale du Portugais Brésilien Parlé à Rio de Janeiro. Tese de Doutorado. Université de la Sorbonne Nouvelle.

Nimuendaju, Curt. 1981. Mapa Etno-bistórico de Curt Nimuendajú. Rio de Janeiro: Fundação Instituto Brasileiro de Geografia e Estatística/ Fundação Pró-Memória. 
Perini, Mario Alberto. 1973. The Process of Nasalization: Evidence from Portuguese, Ms.

Philipson, Jurn J. 1947. O parentesco Tupi-Guarani. (Trad. de Mattoso Câmara Jr. da resenha de George L. Trager). Boletim de Filologia, 2: 7. 180-181. Rio de Janeiro: Dois Mundos.

Pontes, Eunice. 1972. Estrutura do Verbo no Português Coloquial. Rio de Janeiro: Vozes.

RameH, Cléa. 1961. Contrastive Analysis of Portuguese Intonation. Dissertação de Mestrado. Universidade de Georgetown, Washington, D.C.

Reed, W. David e Yolanda Leite. 1956. The Segmental Phonemes of Brazilian Portuguese: Standard Paulista Dialect. In: Pike, Kenneth (ed.). Phonemics: a Technique for Reducing Language to Writing. 5a. ed. Ann Arbor: The University of Michigan Press.

Saint Clair, R. N. 1971. The Portuguese Plural Formation. Linguistics, 68: 90-192.

SAPIR, Edward. 1954[1938]. A linguagem: Introdução ao Estudo da Fala. (Trad. de J. Mattoso Câmara Jr.). Rio de Janeiro: Instituto Nacional do Livro.

1961. Lingüística como Ciência: Ensaios. Seleção, tradução e notas de J. Mattoso Câmara Jr. Rio de Janeiro: Acadêmica.

Santos, Emmanoel Maria Santíssima Trindade José dos. 1973. O Adolescente e a Percep̧̧ão do Valor Social de Variantes Lingüísticas. Dissertação de Mestrado. Faculdade de Letras, UFRJ.

1981. A Transmissão aos Educandos de Crenças e Atitudes Escolares. Tese de Doutorado. Faculdade de Letras, UFRJ.

UchôA, Carlos Eduardo Falcão. 1972. (sel. e introdução.) Dispersos de J. Mattoso Câmara Jr. Rio de Janeiro: Fundação Getúlio Vargas. 